\title{
A study of platelet disorders in pregnancy
}

\author{
Uma Pandey* \\ Department of Obstetrics and Gynaecology, Institute of Medical Sciences, Banaras Hindu University, Varanasi, Uttar \\ Pradesh, India
}

Received: 24 May 2016

Accepted: 13 June 2016

\section{*Correspondence:}

Dr. Uma Pandey,

E-mail: uma.pandey2006@yahoo.com

Copyright: (C) the author(s), publisher and licensee Medip Academy. This is an open-access article distributed under the terms of the Creative Commons Attribution Non-Commercial License, which permits unrestricted non-commercial use, distribution, and reproduction in any medium, provided the original work is properly cited.

\section{ABSTRACT}

Background: Thrombocytopenia is low platelet count, if present during pregnancy can jeopardize the maternal and fetal outcome. Thrombocytopenia affects $6-15 \%$ of pregnancies. Causes of thrombocytopenia include gestational, idiopathic thrombocytopenia, preeclampsia, HELLP, DIC, malignancy and marrow failure.

We planned to do this study to find out common causes of thrombocytopenia in our hospital and management being used.

Methods: Data was collected form those women who came to the antenatal clinic (booked) and labour room (unbooked) in the department of obstetrics and gynaecology, Sir Sunder Lal hospital, institute of medical sciences, Banaras Hindu University. Data of a total of 67 pregnant women were collected during the period of July 2012 to June 2015.

Results: There were $74.62 \%$ cases of gestational thrombocytopenia, $10.44 \%$ related to preeclampsia, $4.47 \%$ in Eclamptic patients, $1.49 \%$ in HELLP and DIC, $5.97 \%$ in ITP, and lastly $1.49 \%$ in malaria cases. There were number of associated complication whether directly related (PPH) or part of the disorder. PPH was observed in $22.38 \%$ which is maximum among all complications. Other complications were part of major associated illness i.e. liver failure (7.46\%), renal failure (4.47\%), DIC (4.47\%) and HELLP (7.46\%).

Conclusions: Mode of delivery was not influenced by platelet count, but for obstetric indications. Management of patients was as per the diagnosis. Single donor plasma is preferable to random donor plasma. PPH was the commonest complication and we should be wary of that.

Keywords: Thrombocytopenia, Postpartum haemorrhage, Preeclampsia, ITP, HELLP, DIC

\section{INTRODUCTION}

Thrombocytopenia is low platelet count, if present during pregnancy can jeopardize the maternal and fetal outcome. Thrombocytopenia affects $6-15 \%$ of pregnancies. The increasing report of thrombocytopenia is also be attributed to better antenatal check-ups and performance of investigation like complete blood count (CBC). ${ }^{1}$
It is defined as platelet count less than $150 \mathrm{X} 10 \wedge 9 / 1$. Pregnancy does per se alter platelet level to a great extent but slight changes takes place, which are more pronounced towards term.

Causes of thrombocytopenia include gestational, idiopathic thrombocytopenia, preeclampsia, HELLP, DIC, malignancy and marrow failure. ${ }^{2-4}$ 
We planned to do this study to find out common causes of thrombocytopenia in our hospital and management being used.

\section{METHODS}

Data was collected form those women who came to the antenatal clinic (booked) and labour room (unbooked) in the department of obstetrics and gynaecology, Sir Sunder Lal Hospital, institute of medical sciences, Banaras Hindu University. Data of a total of 67 pregnant women were collected during the period of July 2012-June 2015.

Data collection was done on a pre-prepared proforma, which collected details of their antenatal history ie gestational age, risk factors, past obstetric history; and medical history ie viral infection, history of bleeding from gingiva, nose, skin petechiae, along with sociodemographic details. History of drug use was also taken. Thorough physical examination including obstetric examination was performed and noted.

At the time of booking and labour room admission it is customary to do complete blood count of all gravid women in our set up. Routinely patients are investigated for HBsAg and HIV antenatally. If thrombocytopenia was observed then patient was investigated further. Bleeding time, clotting time and Coagulation test (PT, APTT) were done. Liver function test, renal function test and check up for infections like dengue fever were done if symptoms were suggestive. Platelet count was repeated monthly if was found thrombocytopenic.

Patients were followed up through-out their gestational period. Feto-maternal outcomes were recorded. Any complication during antenatal period and delivery was noted. Mode of delivery, complications during delivery and postpartum complications in mother and NICU admission, neonatal outcome and birth weight of baby was recorded.

\section{RESULTS}

Table 1 Classification of thrombocytopenia as per etiology.

\begin{tabular}{|lll|}
\hline Cause & Number=67 & Percentage \\
\hline Gestational & 50 & $74.62 \%$ \\
\hline Preeclampsia & 7 & $10.44 \%$ \\
\hline Eclampsia & 3 & $4.47 \%$ \\
\hline HELLP & 1 & $1.49 \%$ \\
\hline AFE & 0 & 0 \\
\hline DIC & 1 & $1.49 \%$ \\
\hline ITP & 4 & $5.97 \%$ \\
\hline Hypersplenism & 0 & 0 \\
\hline Malaria & 1 & $1.49 \%$ \\
\hline
\end{tabular}

There were $74.62 \%$ cases of gestational thrombocytopenia, $10.44 \%$ related to preeclampsia,
$4.47 \%$ in eclamptic patients, $1.49 \%$ in HELLP and DIC, $5.97 \%$ in ITP, and lastly $1.49 \%$ in malaria cases (Table 1).

$4.47 \%$ cases had severe thrombocytopenia $(<10,000)$, $16.41 \%$ cases $(<50,000)$ while $25.37 \%$ had $50,000-1$ lac and $53.73 \%$ had between 1-1.5 lac (Table 2). Majority of the patients were in 18-25 years of age group and multigravida females (Table 3 and 4).

Table 2: Severity of thrombocytopenia.

\begin{tabular}{|lll|}
\hline Platelets levels & Number of cases $=67$ & Percentage \\
\hline$<10,000$ & 3 & $4.47 \%$ \\
\hline $10,000-50,000$ & 11 & $16.41 \%$ \\
\hline $50,000-1 \mathrm{Lac}$ & 17 & $25.37 \%$ \\
\hline $1 \mathrm{Lac}-1.5 \mathrm{Lac}$ & 36 & $53.73 \%$ \\
\hline
\end{tabular}

Table 3: Age.

\begin{tabular}{|lll|}
\hline Age in years & Number & Percentage \\
\hline $18-25$ & 44 & $65.67 \%$ \\
\hline $26-35$ & 21 & $31.34 \%$ \\
\hline $36-46$ & 2 & $2.98 \%$ \\
\hline
\end{tabular}

Table 4: Parity.

\begin{tabular}{|lll|}
\hline Parity & Number & Percentage \\
\hline Primi & 23 & $34.32 \%$ \\
\hline Multi & 44 & $65.67 \%$ \\
\hline
\end{tabular}

Table 5: Maternal outcome.

\begin{tabular}{|l|l|l|}
\hline Maternal complications & Number=67 & Percentage \\
\hline PPH & 15 & $22.38 \%$ \\
\hline Liver failure & 5 & $7.46 \%$ \\
\hline Renal failure & 3 & $4.47 \%$ \\
\hline DIC & 3 & $4.47 \%$ \\
\hline HELLP & 5 & $7.46 \%$ \\
\hline Maternal death & 0 & $0 \%$ \\
\hline
\end{tabular}

There were number of associated complication whether directly related $(\mathrm{PPH})$ or part of the disorder. $\mathrm{PPH}$ was observed in $22.38 \%$ which is maximum among all complications. Other complications were part of major associated illness i.e. liver failure $(7.46 \%)$, renal failure (4.47\%), DIC (4.47\%) and HELLP (7.46\%).

Mode of delivery was decided based on the obstetric factors or medical factors. In this group there were $36 \%$ vaginal deliveries and rest were caesarean sections. Percentage of preterm babies born in this group was $48 \%$.

\section{DISCUSSION}

Obstetric thrombocytopenia is a condition in which obstetric conditions i.e. severe preeclampsia. HELLP, DIC, abruption have resulted in thrombocytopenia whilst 
if it is ITP (Idiopathic thrombocytopenic purpura) then it is a medical condition to be dealt with during pregnancy. Thrombocytopenia increases the risk of PPH, while the other associated obstetric and medical conditions (mentioned above along with anaemia and sepsis) increase the risk of multiple organ failure and maternal mortality. ${ }^{5-7}$

Mode of delivery was not influenced by platelet count, but for obstetric indications. Caesarean sections were done for abruption, severe preeclampsia, eclampsia, previous caesarean section, failed induction or failed progress of labour. Neonates were examined for any hematomas and investigated for platelet count. ${ }^{8}$

Random donor platelets or single donor platelets were used depending upon the availability. In case of PPH blood and blood products were used. Steroids were continued in patients of ITP with medical consultation. Follow up was done by monthly platelet count.

Gestational thrombocytopenia is the commonest cause of low platelet during pregnancy but other medical disorder must be excluded by through history, physical examination, and investigations.

If thrombocytopenia was preexisting then a medical disorder is more likely while if it develops during pregnancy gestational cause is more likely. Primary immune thrombocytopenia was managed as per protocol. ${ }^{9}$

\section{CONCLUSION}

Mode of delivery was not influenced by platelet count, but for obstetric indications. Management of patients was as per the diagnosis. Single donor plasma is preferable to random donor plasma. PPH was the commonest complication and we should be wary of that.
Funding: No funding sources Conflict of interest: None declared

Ethical approval: The study was approved by the Institutional Ethics Committee

\section{REFERENCES}

1. Boehlen F. Thrombocytopenia during pregnancy. Importance, diagnosis and management. Hamostaseologie. 2006;26(1):72-4.

2. Stirling Y, Woolf L, North WR, Seghatchian MJ, Meade TW. Haemostasis in normal pregnancy. Thromb Haemostas. 1984;52:176-82.

3. Matthews JH, Benjamin S, Gill DS, Smith NA. Pregnancy associated thrombocytopenia: definition, incidence and natural history. Acta Haematol Basel. 1990;84:24-9.

4. Fenton V, Saunders K, Cavillet I. The platelets count in pregnancy. J Clin Path. 1977;30:68-9.

5. Shehata N, Burrows RF, Kelton JG. Gestational thrombocytopenia. Clin Obstet Gynecol. 1999;42:327-34.

6. American College of Obstet Gynecol. ACOG practice bulletin: diagnosis and management of preeclampsia in pregnancy. Obstet Gynecol. 2002;99:159-67.

7. Barton JR, Sibai BM. Diagnosis and management of hemolysis, elevated liver enzymes and low platelets syndrome. Clin Perinatology. 2004;31:807-33.

8. Sullivan CA, Martin JN. Management of the obstetric patient with thrombocytopenia. Clin Obstet Gynecol. 1995;38(3):521-34.

9. Provan D, Stasi R, Newland AC, Blanchette VS, Maggs PB, Bussel JB, et al. International consensus report on the investigation and management of primary immune thrombocytopenia. Blood. 2010;115:168-86.

Cite this article as: Pandey U. A study of platelet disorders in pregnancy. Int J Reprod Contracept Obstet Gynecol 2016;5:2377-9. 